\title{
A 25-Year History of Leg Ulceration: Cutaneous Blastomycosis
}

\author{
Ömer Faruk Elmas, ${ }^{1}$ Belkiz Uyar, ${ }^{1}$ Asuman Kilitçi ${ }^{2}$
}

\begin{abstract}
1 Department of Dermatology, Faculty of Medicine, Kırşehir Ahi Evran University, Kırşehir, Turkey
\end{abstract}
2 Department of Pathology, Faculty of Medicine, Kırşehir Ahi Evran University, Kırşehir, Turkey

Key words: cutaneous blastomycosis, dermoscopy, histopathology, pyoderma gangrenosum

Citation: Elmas ÖF, Uyar B, Kilitçi A. A 25-year history of leg ulceration: cutaneous blastomycosis. Dermatol Pract Concept. 2020;10(3):e2020054. DOI: https://doi.org/10.5826/dpc.1003a54

Accepted: March 12, 2020; Published: June 29, 2020

Copyright: $\odot 2020$ Elmas et al. This is an open-access article distributed under the terms of the Creative Commons Attribution License, which permits unrestricted use, distribution, and reproduction in any medium, provided the original author and source are credited.

Funding: None.

Competing interests: The authors have no conflicts of interest to disclose.

Authorship: All authors have contributed significantly to this publication.

Corresponding author: Dr. Ömer Faruk Elmas, Department of Dermatology, Kırşehir Ahi Evran University, Kırşehir, 40000, Turkey. Email: omerfarukmd@gmail.com

\section{Introduction}

Blastomycosis is a fungal infection caused by Blastomyces dermatitidis. It is characterized by a chronic granulomatous and suppurative inflammatory reaction [1]. Cutaneous blastomycosis (CB) usually develops after hematogenous dissemination from primary lung involvement. However, less commonly, Blastomyces dermatitidis can be inoculated into the skin, causing primary cutaneous blastomycosis. The skin involvement in $\mathrm{CB}$ includes a wide variety of manifestations ranging from papulopustular and nodular lesions to verrucous and ulcerative lesions [2]. We report a case of CB initially misdiagnosed as pyoderma gangrenosum (PG).

\section{Case Presentation}

A 64-year-old woman with a nonhealing ulceration on the left leg was referred to us with a preliminary diagnosis of PG. The lesion first appeared 25 years ago and had grown in size without any response to many treatments, including topical and systemic antibiotics and corticosteroids. There was no history of a trauma to the area or a known inciting cause. There was also no history of a respiratory infection.
Dermatological examination revealed a painless vegetative ulceration $18 \times 10 \mathrm{~cm}$ in size on the anterior aspect of the left leg (Figure 1). On the dermoscopic examination, white to pinkish overlapping papillomatous structures, white and red structureless areas, blood spots, and polymorphous vessels including dotted, coiled, serpentine, and complex looped vessels with an annular arrangement were observed (Figure 2). Direct microscopic examination of the skin-scraping material revealed the fungal element. The histopathological examination showed ulceration, pseudoepitheliomatous hyperplasia, predominantly neutrophilic inflammatory infiltrate, and broad-based bugging yeasts consistent with Blastomyces dermatitidis (Figure 3). A detailed workup revealed no evidence of systemic involvement. A 200-mg daily dose of itraconazole was started; considerable improvement was observed after 3 months.

\section{Conclusions}

$\mathrm{CB}$ is a rare and often misdiagnosed cause of persistent leg ulceration. The common misdiagnoses include scrofuloderma, granuloma inguinale, nocardiosis, cutaneous tuberculosis, as well as squamous cell carcinoma. Our patient was initially 
misdiagnosed with PG and underwent systemic corticosteroid treatment, which did not lead to remarkable improvement. PG is a neutrophilic dermatosis characterized by painful ulcerative lesions usually located on extremities. On histopathological examination, PG usually shows ulceration, pseudoepitheliomatous hyperplasia, and neutrophil-rich dermal inflammatory infiltration, which can also be seen in CB. The significant clinicopathological overlap between CB and PG may cause misdiagnosis. The diagnosis of recalcitrant leg ulcerations including PG is mainly based on the exclusion and histopathological examination is usually performed. In this context, pathology specimens submitted should always be examined carefully to rule out $\mathrm{CB}$. It should also be kept in mind that in a case of $\mathrm{CB}$, the misdiagnosis of PG followed by systemic corticosteroid therapy may cause fatal complications such as disseminated blastomycosis and acute respiratory distress syndrome [2,3].

\section{References}

1. Mason AR, Cortes GY, Cook J, Maize JC, Thiers BH. Cutaneous blastomycosis: a diagnostic challenge. Int J Dermatol. 2008;47(8):824-830. https://doi. org/10.1111/j.1365-4632.2008.03732.x.

2. Azar MM, Relich RF, Schmitt BH, Spech RW, Hage CA. Cutaneous blastomycosis masquerading as pyoderma gangrenosum. J Clin Microbiol. 2014;52(4):1298-1300. https://doi.org/10.1128/JCM.03356-13.

3. Mak J, Al Habeed A, Al Kalabi M, Alavi A. Pyoderma gangranosum-like blastomycosis. J Cutan Med Surg. 2018;22(5):519521. https://doi.org/10.1177/120347541 8760460.

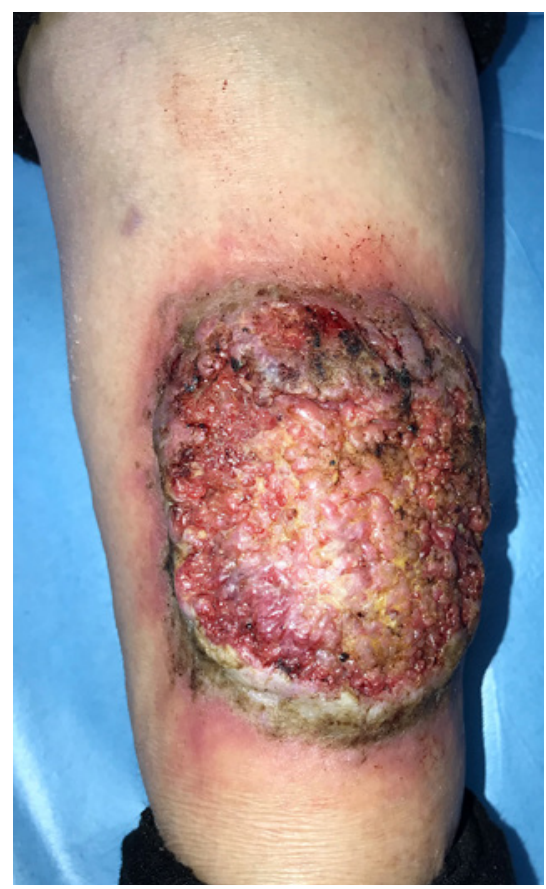

Figure 1. Vegetative ulceration $18 \times 10 \mathrm{~cm}$ in size on anterior aspect of the left leg.

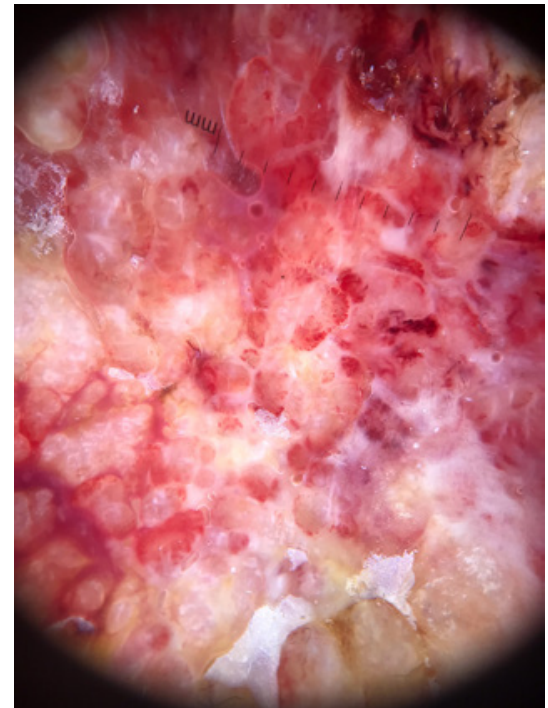

Figure 2. Dermoscopy shows white to pinkish overlapping papillomatous structures, white and red structureless areas, blood spots, and polymorphous vessels including dotted, coiled, serpentine complex looped vessels with an annular arrangement.



Figure 3. (A) Low-power histopathological view shows ulceration, pseudoepitheliomatous hyperplasia, and dermal inflammatory infiltration (H\&E, $\times 100)$. (B) Broad-based bugging yeasts consistent with Blastomyces dermatitidis $(\mathrm{H} \& \mathrm{E}, \times 400)$. 